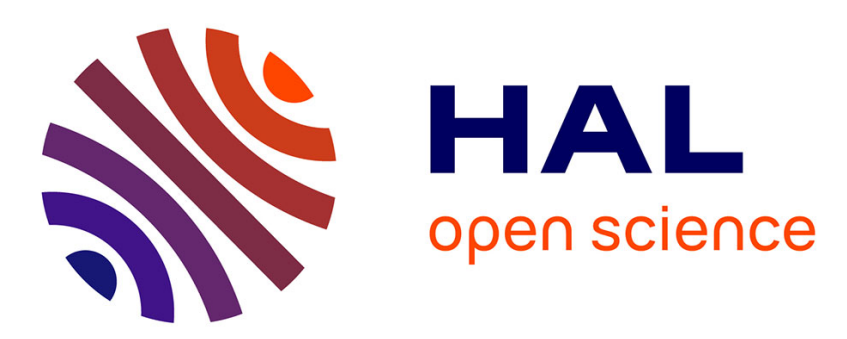

\title{
A model for describing the light response of the nonphotochemical quenching of chlorophyll fluorescence
}

\author{
Joao Serôdio, Johann Lavaud
}

\section{To cite this version:}

Joao Serôdio, Johann Lavaud. A model for describing the light response of the nonphotochemical quenching of chlorophyll fluorescence. Photosynthesis Research, 2011, 108, pp.61-76. 10.1007/s11120011-9654-0 . hal-01096561

\section{HAL Id: hal-01096561 \\ https://hal.science/hal-01096561}

Submitted on 17 Dec 2014

HAL is a multi-disciplinary open access archive for the deposit and dissemination of scientific research documents, whether they are published or not. The documents may come from teaching and research institutions in France or abroad, or from public or private research centers.
L'archive ouverte pluridisciplinaire HAL, est destinée au dépôt et à la diffusion de documents scientifiques de niveau recherche, publiés ou non, émanant des établissements d'enseignement et de recherche français ou étrangers, des laboratoires publics ou privés. 
1 A model for describing the light response of the non-photochemical quenching of chlorophyll

2 fluorescence

6 João Serôdio

7 Departamento de Biologia and CESAM - Centro de Estudos do Ambiente e do Mar,

8 Universidade de Aveiro, Campus de Santiago, 3810-193, Aveiro, Portugal

$10 \quad$ Johann Lavaud

11 UMR CNRS 6250 'LIENSs', Institute for Coastal and Environmental Research (ILE),

12 University of La Rochelle, 2 rue Olympe de Gouges, 17000 La Rochelle, France

20 Corresponding author: J. Serôdio

21 e-mail: jserodio@ua.pt; Tel: +351 234370787; Fax: +351 234372587 
The operation of photosynthetic energy-dissipating processes is commonly characterised by measuring the light response of the non-photochemical quenching (NPQ) of chlorophyll fluorescence, or NPQ vs. $E$ curves. This study proposes a mathematical model for the quantitative description of the generic NPQ vs. $E$ curve. The model is an adaptation of the Hill equation and is based on the close dependence of NPQ on the xanthophyll cycle (XC). The model was tested on NPQ vs. E curves measured in the plant Arabidopsis thaliana and the diatom Nitzschia palea, representing the two main types of XC, the violaxanthinantheraxanthin-zeaxanthin (VAZ) type and the diadinoxanthin-diatoxanthin (DD-DT) type, respectively. The model was also fitted to a large number of published light curves, covering the widest possible range of XC types, taxa, growth conditions, and experimental protocol of curve generation. The model provided a very good fit to experimental and published data, coping with the large variability in curve characteristics. The model was further used to quantitatively compare the light responses of NPQ and of PSII electron transport rate, ETR, through the use of indices combining parameters of the models describing the two types of light-response curves. Their application to experimental and published data showed a systematic large delay of the build-up of NPQ relatively to the saturation of photochemistry. It was found that when ETR reaches saturation, NPQ is on average still below one fifth of its maximum attainable level, which is only reached at irradiances about three times higher. It was also found that organisms Keyword index: Chlorophyll fluorescence; modelling; non-photochemical quenching; 
Photosynthesis requires a balance between maximizing light absorption and minimizing damages caused by excessively absorbed light energy. Under natural conditions, exposure to sunlight involves unavoidable risks to the photosynthetic apparatus due to the formation of reactive oxygen species of photosynthetic origin produced under excess light (Osmond et al. 1997; Ort 2001; Demmig-Adams and Adams 2006). The sustainment of prolonged photosynthetic activity under high solar irradiances is ensured by the regulation of the repartition of absorbed light energy between photochemistry and energy-dissipating pathways. The latter function as photoprotective process against permanent damages to the photosynthetic apparatus, or photoinhibition, and are therefore of considerable interest for understanding the resistance of photoautotrophs to environmental stress (Demmig-Adams and Adams 2006; Lavaud 2007; Li et al. 2009).

One of the most important photoprotective processes is the non-photochemical quenching (NPQ). NPQ groups several pathways among which the thermal dissipation of excess energy (or $q_{\mathrm{E}}$, the energy-dependent quenching, Müller et al., 2001) is considered as the most important. $q_{\mathrm{E}}$ takes place in the light-harvesting antenna of the photosystem II (PS II). It relies on the presence of specific PS II antenna proteins (PsbS in plants, Li et al. 2000; LhcSR in green microalgae, Peers et al. 2009; Lhcx in diatoms, Bailleul et al. 2010), the building of a transthylakoid proton gradient $(\Delta \mathrm{pH})$, and the subsequent enzyme-mediated operation (deepoxidation) of the xanthophyll cycle (XC) (Goss and Jakob, 2010). The XC produces deepoxidised forms of xanthophylls which are essential regulatory partners of $q_{\mathrm{E}}$, especially in some groups of microalgae (like the diatoms) (Lavaud, 2007; Li et al. 2009; Goss and Jakob 2010). In plants, green algae and some Heterokontophyta (brown algae, Chrysophyceae), the $\mathrm{XC}$ is based on the reversible conversion of pigment violaxanthin $(\mathrm{Vx})$ to the $q_{\mathrm{E}}$-involved zeaxanthin (Zx), passing through the intermediate form antheraxanthin (Ax) (VAZ type of XC); in other algal groups, like the diatoms, dinoflagellates, Xanthophyceae and Haptophyta, the XC consists in the conversion between only two pigments, diadinoxanthin (DD) and the $q_{\mathrm{E}}$-involved 
80 Lavaud 2007). In phycobilisome-containing organisms, there is no XC (cyanobacteria) or its

81 presence is uncertain (red algae) (Goss and Jakob 2010). index NPQ, which is based on the relative difference between the maximum fluorescence measured in the dark-adapted state, $F_{\mathrm{m}}$, and upon exposure to light, $F_{\mathrm{m}}{ }^{\prime}$ (see Table 1 for

86 notation):

$$
\mathrm{NPQ}=\frac{F_{m}-F_{m}^{\prime}}{F_{m}^{\prime}}
$$

This index is a rearrangement of the Stern-Volmer equation and reflects the assumption that the reciprocal of fluorescence yield is proportional to the Zx or DT concentration (Bilger and Björkman 1990; Lavaud et al. 2002; Baker and Oxborough 2004). The NPQ index has been routinely used to quantify the operation of photoprotective processes as well as the extent of photoinhibitory damages. Under experimental conditions allowing to assume that the prevailing processes causing the quenching of fluorescence are of photoprotective nature, NPQ has been used as a measure of the overall photoprotective capacity of the photosynthetic apparatus (e.g. Dimier et al. 2007b; Lavaud et al. 2007). susceptibility to photoinhibition is to quantify the light response of NPQ. This is done by constructing NPQ vs. $E$ curves that record the development of NPQ with increasing incident irradiance. These curves are analogous to the more frequently measured light-response curves of the PSII electron transport rate (ETR) in the sense that they represent the variation of steady state photosynthetic activity between different light levels, thus not informing on the kinetics of NPQ generation, but on the NPQ attainable under each irradiance. The shape of NPQ vs. $E$ curve varies widely, both regarding its overall shape as well as the absolute NPQ values 
reached. Typically, NPQ increases monotonically with irradiance, varying from zero (measured

107 in darkness) to maximum values that vary greatly with taxonomical groups, physiological state,

108 environmental constraints, or light levels applied. The curve presents a variable degree of

109 sigmoidicity, ranging from cases when NPQ starts to increase steeply from the lowest light

110 levels, following a simple saturation-like pattern (no sigmoidicity), to cases when NPQ remains

111 close to zero for a range of low light levels, then showing an abrupt increase only for

112 intermediate irradiances before stabilizing at maximum values (highly sigmoid). Often,

113 although the stabilization of NPQ is evident, a constant value is not reached within the range of

114 irradiances applied and the maximum attainable NPQ cannot be estimated.

115 Light-response curves of NPQ have been analysed and interpreted on the basis of

116 arbitrarily chosen features, by qualitatively describing its shape (e.g. low or high sigmoidicity),

117 or by selecting NPQ values reached at particular $E$ levels (e.g. NPQ at maximum applied $E$ ).

118 The absence of an adequate descriptive model impedes the characterization of the curve along

119 the whole range of irradiances applied. Also, the lack of a commonly-used set of descriptive

120 parameters makes it difficult to compare curves measured in different studies or experimental

$121 \quad$ conditions or taxonomic groups.

The present study proposes a simple mathematical model for the quantitative description of the generic NPQ vs. $E$ curve, by means of the estimation of a small number of

124 physiologically-meaningful parameters. The model is based on the close, but not absolute,

125 dependence of NPQ on the operation of the XC, through the light-induced de-epoxidation of PS

126 II antenna pigments Vx or DD. To illustrate the main features and variability of the NPQ vs. $E$

127 curve, as well as the interpretation of model parameters, light-response curves were measured

128 on a plant (Arabidopsis thaliana (L.); VAZ type XC) and a diatom (Nitzschia palea (Kütz) W.

129 Smith; DD-DT type XC) grown under experimental conditions expected to induce a large

130 variability in curve shape and NPQ absolute values. The adequacy of the model was further

131 tested by fitting it to published NPQ vs. $E$ curves measured on a large variety of photosynthetic

132 organisms and experimental conditions, and covering the widest possible range of NPQ values

133 and curve shapes. The usefulness of the model was also illustrated by exploring the relationship 
134 between NPQ vs. $E$ curves and the photoacclimation status, characterized by light-response

135 curves of the PSII electron transport rate, ETR.

136

137

138

Materials and Methods

139

$140 \quad$ Model rationale

141

142 The model proposed to describe the light-response curve of NPQ is an adaptation of the Hill

143 equation, originally derived in the context of ligand binding to macromolecules with multiple

144 binding sites. This equation describes the variation of the number of filled binding sites with the

145 increase in ligand concentration, and is routinely used to characterise the cooperativity of

146 enzymatic reactions (Voet and Voet 1990). The use of the Hill equation for modelling the NPQ

147 vs. $E$ curve is based on the main assumption that NPQ is mostly due to the operation of the XC

148 coupled to the build-up of the transthylakoid $\Delta \mathrm{pH}$, or energy-dependent quenching $\left(q_{\mathrm{E}}\right.$; Müller

149 et al. 2001), and that the other potential components of NPQ, the quenching due to state

150 transitions $\left(q_{\mathrm{T}}\right)$ or to photoinhibition $\left(q_{\mathrm{I}}\right)$ are not expected to significantly affect the NPQ vs. $E$

151 curves (see Discussion). The analogy underlying this rationale is to consider the epoxidized XC

152 pigments Vx and DD as representing the macromolecule of the Hill model, and the

153 transthylakoidal $\Delta \mathrm{pH}$-dependent protonation of specific light-harvesting complex (LHC)

154 antenna sites as corresponding to the ligand concentration that bind to their multiple binding

155 sites. At steady state, each irradiance level corresponds to a stable transthylakoidal $\Delta \mathrm{pH}$ and

156 resulting Vx or DD de-epoxidation and activation through protonation of LHC sites (the so-

157 called 'activation' of Zx and DT; Horton et al. 2000; Goss et al. 2006; Lavaud and Kroth 2006;

158 Horton et al. 2008), and thus to a defined NPQ value. The NPQ vs. $E$ curve is thus proposed to

159 be described by the equation:

160 

where $\mathrm{NPQ}_{\mathrm{m}}$ is the maximum NPQ value reached during the light curve, $E_{50}$ is the irradiance

164 level for which NPQ attains $50 \%$ of $\mathrm{NPQ}_{\mathrm{m}}$, and $n$ is the Hill coefficient, characterizing the 165 sigmoidicity of the curve. Whilst the parameters $E_{50}$ and $n$ are directly adopted from the Hill 166 equation (originally having only these two parameters), a third parameter, $\mathrm{NPQ}_{\mathrm{m}}$, had to be 167 considered to account for the variability in the absolute values of NPQ. Under the analogy with the ligand binding context of the Hill equation, $\mathrm{NPQ}(E)$ is considered to represent the fraction of Vx or DD molecules de-epoxidized into Zx or DT and which have been 'activated'. As such, $E_{50}$ represents the irradiance level necessary to de-epoxidize and 'activate' $50 \%$ of convertible

171 Vx or DD pool (ligand concentration resulting in half occupation of binding sites) necessary to 172 reach the maximal NPQ level, $\mathrm{NPQ}_{\mathrm{m}}$. Of potential importance for the characterization of the 173 physiological processes underlying the NPQ vs. $E$ curve is the sigmoidicity parameter $n$, which 174 measures the type and extent of the reaction cooperativity. In the case of $n<1$, the curve displays a saturation-like increase asymptotically towards $\mathrm{NPQ}_{\mathrm{m}}$, indicating the presence of a negatively cooperative reaction; if $n>1$, the curve starts to present a sigmoidal shape, the sigmoidicity increasing with $n$, indicating a positively cooperative, or allosteric, reaction; if $n$

$178=1$, the model is reduced to the Michaelis-Menten equation, indicative of a non-cooperative 179 reaction. To test the adequacy of the model, Eq. 2 was first fit to NPQ vs. $E$ curves generated for 184 organisms representative of the two types of XC, a plant (A. thaliana; VAZ type of XC) and a 185 diatom (N. palea; DD-DT type of XC), grown under light conditions expected to induce large 186 variations in NPQ absolute values and in the shape of the NPQ light-response curve. Plants of 

were $22 / 20{ }^{\circ} \mathrm{C}$. Three irradiance levels were applied: 10 ('low light', LL), 75 ('moderate light', ML) and $150 \mu \mathrm{mol}$ photons $\mathrm{m}^{-2} \mathrm{~s}^{-1}$ ('high light', HL). The diatom Nitzschia palea (Kütz.) W. Smith (collection of the Department of Biology, University of Aveiro) was grown photoautotrophically in unialgal semi-continuous batch $100 \mathrm{~mL}$ cultures in sterile natural seawater enriched with f/2 nutrients (Guillard and Ryther 1962). Cultures were grown at $20{ }^{\circ} \mathrm{C}$, under 20 (LL), 100 (ML) and $400 \mu \mathrm{mol}$ photons $\mathrm{m}^{-2} \mathrm{~s}^{-1}$ (HL) in a 12:12 h light/dark cycle. Cells were harvested by centrifugation $(3000 \times \mathrm{g}, 10 \mathrm{~min})$ during the exponential phase of growth, and were resuspended in fresh growth medium supplemented with $\mathrm{NaHCO}_{3}$ to a final concentration > $10 \mu \mathrm{g} \mathrm{Chl} a \mathrm{ml}^{-1}$. Light-response curves of NPQ and ETR were generated by exposing the samples to 712 levels of actinic light, up to $920 \mu \mathrm{mol} \mathrm{m} \mathrm{s}^{-2}$. Samples were dark-adapted for $30 \mathrm{~min}$ before the start of the light curve to allow determination of fluorescence levels $F_{\mathrm{o}}$ (minimum fluorescence) and $F_{\mathrm{m}}$, required for the calculation of NPQ (Eq. 1). Samples were light-activated before the start of each light-response curve, through exposure to low light of $54 \mu$ mol photons $\mathrm{m}^{-2} \mathrm{~s}^{-1}$ until a steady state in fluorescence was reached (minimum $15 \mathrm{~min}$ ). Under each light level, a saturation pulse ( $0.8 \mathrm{~s}$ for A. thaliana and $0.6 \mathrm{~s}$ for $N$. palea $)$ was applied and fluorescence levels $F_{\mathrm{s}}$ (steady state fluorescence) and $F_{\mathrm{m}}{ }^{\prime}$ were recorded and used to calculate NPQ (Eq. 1) and ETR, using (Genty et al. 1989): A different sample (plant leaf or algal culture aliquot) was used for measuring NPQ and ETR 211 under each light level. Three replicated measurements were made for each light level. Light212 response curves of ETR were described by fitting the model of Eilers and Peeters (1988), and by 213 estimating the parameters $\alpha$ (the initial slope of the curve), ETR $_{\mathrm{m}}$ (maximum ETR) and $E_{\mathrm{k}}$ (the 214 light-saturation parameter). The parameter $E_{\mathrm{k}}$ is commonly interpreted as a measure of the light 
215 level to which a sample is acclimated to, and commonly used to characterise its

216 photoacclimation status (Behrenfeld et al. 2004).

Chlorophyll fluorescence yield was measured using a PAM fluorometer comprising a computer-operated PAM-Control Unit (Walz) and a WATER-EDF-Universal emitter-detector unit (Gademann Instruments GmbH, Germany), using a modulated blue light (LED-lamp peaking at $450 \mathrm{~nm}$, half-bandwidth of $20 \mathrm{~nm}$ ) as source for measuring, actinic, and saturating light (Cruz and Serôdio 2008). Fluorescence was measured using a 6 mm-diameter Fluid Light Guide fiberoptics. In the case of $N$. palea, the fiberoptics was connected to a fluorescence cuvette (KS-101, Walz, Effeltrich, Germany).

Published light-response curves

The model was also fitted to published NPQ vs. $E$ curves, covering a wide range of taxonomic groups (higher plants, mosses, green algae, diatoms, dinoflagellates, others), XC types (VAZ, DD-DT, absence of XC), mutants with variable degrees of impairment of the XC operation, habitats (land and aquatic higher plants; planktonic and benthic microalgae), growth conditions (e.g. low and high light), physiological state (heat stress or XC inhibitors) and fluorescence light-response curve measuring protocols (steady state and rapid light curves, RLCs). Only species with a known functional XC were considered. Studies presenting light curves having less than seven data points were not considered, because of the large errors in the model fitting and parameter estimation. For each study, when three or more light curves were available for each species and experimental treatment, only the two curves presenting the most extreme (higher and lower) NPQ values were used. Detailed information on the data used in the metaanalysis is summarised in Table 3. When available, the corresponding ETR vs. $E$ curves were also characterised by fitting the model of Eilers and Peeters (1988) and by estimating its parameters.

Some studies have reported the formation of NPQ in the dark (Perkins et al. 2010). This phenomenon was observed on diatoms (Jakob et al. 1999) and brown algae (Mouget and 
244 NPQ decreasing from initial high values measured in the dark to a minimum under low to

245 moderate light levels (e.g. Geel et al. 1997; Serôdio et al. 2006). Being relevant only for a

246 limited number of taxonomic groups and physiological conditions, this type of NPQ light-

247 response curve was not considered in the present study.

249 Model fitting and parameter estimation

The light-response curve models were fitted using a procedure written in Microsoft Visual Basic and based on Microsoft Excel Solver. Model parameters were estimated iteratively by minimizing a least-squares function, forward differencing, and the default quasi-Newton search method. The model can be easily fitted using commonly available software packages. On preliminary tests, this method was compared with the fitting procedures implemented in Sigmaplot 9.0 (Systat Software, Inc., San Jose, USA) and Statistica 8.0 (Statsoft, Inc., Tulsa, USA) and no significant differences were found between the estimates of model parameters. and are asymptotic standard errors. For nonlinear models such as the one here tested, asymptotic standard errors may not be adequate, as they possibly underestimate the actual parameter uncertainty and cannot evaluate the eventual asymmetry of the confidence regions of estimated parameters (Johnson 2008). A number of alternative approaches exist, the best being based on Monte Carlo methods, such as the Boostrap (Press et al. 1996; Johnson 2008). However, the benefits of pursuing alternative methods, requiring substantially more computation time, depend on the magnitude of the uncertainty associated to parameter estimation. In this study, the use of asymptotic standard errors was justified by the finding that they were on average relatively low, in a majority of cases below $10 \%$ of parameter estimates (see below, Results), in which case

\section{Results}


The light-response curves of NPQ measured in the plant A. thaliana and in the diatom N. palea acclimated to different growth light conditions showed a wide range of curve shapes, varying between two main types: curves with low sigmoidicity, presenting a simple saturation-like pattern (e.g. Fig. 1a, HL), and curves with high sigmoidicity, presenting an initial period of low values, followed by a phase of rapid increase leading to a stage of plateau of maximum values (e.g. Fig. 2a, HL). In all cases, the model provided an excellent fitting to the experimental data throughout the whole range of light levels explaining always more than $99.1 \%$ of the data variability (Table 2). Although the residuals (Figs. 1b, 2b) showed in some cases a clearly nonrandom pattern of variation, values were typically low, between $\pm 5 \%$. The fitting of the model resulted in a large variation of model parameters with species and growth light conditions, following some consistent trends. Both for A. thaliana and N. palea, the increase in growth light resulted in an increase in $\mathrm{NPQ}_{\mathrm{m}}$ (Fig. 1a, 2a; Table 2). This increase in $\mathrm{NPQ}_{\mathrm{m}}$ could be detected despite the fact that in most cases the curves did not reach their maximum values within the range of irradiances applied (e.g. Fig. 1a). Another effect of increasing growth light was the increase in the irradiance level for which the curves reached maximum values. For LL-grown samples, maximum NPQ was reached for lower irradiances, with the curves showing an overall lower sigmoidicity, while for HL-grown samples, curves reached saturation at much higher light and $N$. palea was the apparent curve sigmoidicity, with less sigmoid curves being found for the levels. This trend could be well described by model parameter $E_{50}$, which increased with growth light in both species (Table 2).

The most noticeable difference between the NPQ light-response curves of A. thaliana former and more sigmoid curves (and a larger variation) for the latter. This variation in curve sigmoidicity was well characterized by the model parameter $n$, which averaged 1.2 for $A$. thaliana (varying from 0.98 to 1.44 ), whilst reaching an average value of 2.11 for $N$. palea 

species, with $n$ decreasing with growth light in A. thaliana, and increasing in N. palea (Table 2).

The compilation of published light-response curves of NPQ allowed gathering a large number of datasets covering a wide range of NPQ absolute values and curve shapes. The model provided a very good fit to the published data, coping with the large diversity in curve characteristics resulting from different combinations of maximum NPQ values attained $\left(\mathrm{NPQ}_{\mathrm{m}}\right)$, irradiance range of NPQ build-up $\left(E_{50}\right)$, and curve sigmoidicity $(n)$ (Table 3$)$. Considering all cases, the model explained more than $96 \%$ of data variability, independently of type of XC (and $\mathrm{XC}$ impaired mutants), species, growth conditions, and experimental protocol used for the generation of light curves. A summary of the meta-analysis carried out on the data set of published NPQ vs. $E$ curves is presented in Table $4 . \mathrm{NPQ}_{\mathrm{m}}$ was the most variable parameter (c.v. $112.5 \%$ ), mostly responding to growth conditions, averaging 2.89 but reaching maximum values above 9 for diatoms and even higher for some mosses (Table 3). $E_{50}$ ranged from 30-40 $\mu \mathrm{mol}$ photons $\mathrm{m}^{-2} \mathrm{~s}^{-1}$ to above $3500 \mu \mathrm{mol} \mathrm{m} \mathrm{m}^{-2}$, in all cases attaining values well above growth irradiances (see below). However, with few exception (the diatoms Skeletonema costatum and Phaeocystis antarctica, and the high light-grown A. thaliana), all values of $E_{50}$ above 1200 $\mu \mathrm{mol} \mathrm{m} \mathrm{s}^{-2}$ were obtained for A. thaliana mutants with impaired operation of the XC (Table 3). $n$ was the least variable parameter (c.v. 50.8\%), meaning that the curve shape remained relatively unaltered, and that the variability in the NPQ vs. $E$ curves was mainly due to changes in NPQ maximum values and in NPQ onset along the irradiance range. $n$ averaged 1.7, corresponding to a noticeable degree of sigmoidicity, although values around 1.0 (no sigmoidicity) or slightly lower (mostly mutants with impaired XC) as well as above 3.0 (very high sigmoidicity) were also found (Table 3). Despite the low number of data points forming most NPQ vs. E curves, standard errors of parameter estimates were on average relatively low (15.6, 27.3 and $12.2 \%$ of estimates for 
$\mathrm{NPQ}_{\mathrm{m}}, E_{50}$ and $n$, respectively). However, standard errors were typically much higher in the cases when XC was impaired (24.5, 43.9 and $13.5 \%$ for $\mathrm{NPQ}_{\mathrm{m}}, E_{50}$ and $n$, respectively), indicating that a high level of precision in the estimation of model parameters can be expected for samples under natural conditions.

When comparing different XC types, no clear differences were found between model parameters, due to the large overlap of their range of variation. Model parameters appeared to depend mostly on growth conditions, as larger variations could be found within the same species than amongst different taxonomic groups. The model also described very well the lightresponse curves of NPQ for composite samples (phytoplankton, microphytobenthos). Model parameters varied independently from each other, as no significant correlations were found between $\mathrm{NPQ}_{\mathrm{m}}, E_{50}$ or $n$, either when considering all data pooled together, or when considering for separate for each XC type.

Considering the published data, the effects of growth light levels on model parameters were identical to those described for the experimental data of this study. When compared to lower light conditions, NPQ light-response curves of samples acclimated to high light showed higher values of $\mathrm{NPQ}_{\mathrm{m}}$ (Bilger and Bjorkman 1990; Burritt and MacKenzie 2003; Müller et al. 2004; Ralph and Gademann 2005; Rodríguez-Calcerrada et al. 2007; Cruz and Serôdio 2008) and, with the exception of Ralph and Gademann (2005), all these studies showed a similar increase in $E_{50}$ with growth light. The model also fitted very well the light-response curves of

Finally, the model was also found to be adequate to describe NPQ vs. $E$ curves generated under non-steady state conditions, i.e. derived from RLCs. The comparison of the model parameters estimated for light curves of different light steps showed the same pattern on VAZ and DD-DT samples, with shorter light steps resulting in lower $\mathrm{NPQ}_{\mathrm{m}}$ and higher $E_{50}$, whilst $n$ not showing any consistent trend (Ralph and Gademann 2005; Perkins et al. 2006). 
To illustrate the application of the model to evaluate to what extent the NPQ response to light is related to the photoacclimation status, the light levels required for induction of NPQ and for photochemistry or ETR saturation were compared. A simple form of achieving this is by the direct comparison of model parameters $E_{50}$ and $E_{\mathrm{k}}$ estimated for the two types of light-response curves. These parameters have the advantage of being measured in the same scale (PAR irradiance, $\mu \mathrm{mol}$ photons $\mathrm{m}^{-2} \mathrm{~s}^{-1}$ ) and of being independent of the units used to measure photosynthetic rates, ETR or NPQ, which can vary with the method in use (the case of photosynthesis) or instrument settings (the case of ETR).

For the experimental data obtained in this study, the increase in growth irradiance induced a substantial change in the photoacclimation status, noticeable by a clear change in the ETR vs $E$ curves. As a result, the increase observed for $E_{50}$ was followed by a similarly large increase in $E_{\mathrm{k}}$, (due to the decrease of $\alpha$ and the increase of $\mathrm{ETR}_{\mathrm{m}}$ ), both in A. thaliana (Fig. 3) and in $N$. palea (Fig. 4). However, $E_{50}$ was found to be in all cases higher than $E_{\mathrm{k}}$, by 3.7 and 2.5 times, on average, for A. thaliana and N. palea, respectively ( 2.90 for the whole data). This result indicates that the light-induced build-up of substantial values of NPQ started only after linear electron transport reached near saturation. Furthermore, it shows that a large fraction of $E_{50}$ variability was related to variations in the photoacclimation status due to different growth light conditions, as $E_{50}$ increased linearly with $E_{\mathrm{k}}$, both for the plant as for the diatom (although the correlation was not statistical significant, but a clear linear trend is obvious; Fig. 5). This analysis also showed that the slope of the regression line of $E_{50}$ on $E_{\mathrm{k}}$ was higher for A. thaliana than for $N$. palea, indicating that, for the same photoacclimation status (the same $E_{\mathrm{k}}$ ) the plant requires a higher light level for NPQ to reach $50 \%$ of its maximum capacity. Or, in other words, that NPQ is induced latter in the range of irradiances in the plant than in the diatom. Interestingly, the analysis of the subset of published data presenting both NPQ and ETR light-response curves, showed the same generic trend. When pooling together the published and 
experimental data for samples with fully operational XC (i.e. excluding mutants or samples treated with XC inhibitors) and $E_{\mathrm{k}}$ estimates based only on steady state light curves (i.e. excluding RLCs as $E_{\mathrm{k}}$ estimation is largely dependent on light step duration; Serôdio et al. 2006), the ratio $E_{50} / E_{\mathrm{k}}$ was found to be higher on organisms having a VAZ type of XC and to differ significantly from those having a DD-DT type (3.32 and 2.39, respectively; $t$-test $P=$ 0.038; Fig. 6a).

Another way to compare the light responses of NPQ and ETR is to calculate the fraction of NPQ that is formed when ETR approaches saturation (i.e. when $E=E_{\mathrm{k}}$ ), or:

$$
\mathrm{NPQ}{ }_{\mathrm{Ek}}=\frac{\mathrm{NPQ}\left(E_{\mathrm{k}}\right)}{\mathrm{NPQ}_{\mathrm{m}}}
$$
developed (corresponding to high $E_{50} / E_{\mathrm{k}}$ ), whilst high values indicate that NPQ responds more promptly to light increase and the approach of ETR saturation (corresponding to low $E_{50} / E_{\mathrm{k}}$ ). organisms with a VAZ type of XC than for those with the DD-DT type (0.14 and 0.21, respectively; $t$-test, $P=0.023$; Fig. $6 \mathrm{~b})$.

Model fitting and parameter estimation (average 9.7, maximum 13), the model proposed in this study was found to be easily fitted to experimental curves, in most cases yielding parameter estimates virtually independently from the start values used in the iterative fitting procedure (although realistic start values allows a 
more rapid and precise parameter estimation). The main problem found when trying to fit Eq. 2

410 to NPQ vs. $E$ curves occurred when the curves were very close to linear, showing no clear

411 features like sigmoidicity or saturation. This resulted in that a similarly good fit could be

412 reached with different combinations of model parameters values. Still, this occurred only in

413 relatively small number of cases, like the case of the diatom Skeletonema costatum (Lavaud et

414 al. 2007) and some A. thaliana mutants with severe impairment of XC operation, for which

415 some degree of uncertainty remain associated to the presented parameter estimates.

416 This problem seems to result from the common situation of having light-response

417 curves constructed with the main purpose of characterizing the ETR vs. $E$ curves, NPQ having

418 only a secondary interest. As it often happens that the NPQ approaches its maximum for light

419 levels much above the range used for measuring ETR, the NPQ vs. $E$ curve may result truncated

420 and its complete shape may not be available for model fitting. Yet, the relationship established

421 between NPQ and ETR light curves in similar data may be used to impose boundaries to the

422 model parameter estimates, and thus help to reach a single set of meaningful values.

423

424

425

\section{Discussion}

426

427

Model assumptions

428

429 The model proposed for describing the NPQ vs. $E$ curve is based on the main assumption that

430 NPQ is mostly due to $q_{\mathrm{E}}$, the 'energy-quenching' associated to the build-up of the transthylakoid

$431 \Delta \mathrm{pH}$ and the operation of the XC. This assumption is generally supported by the finding of strong linear relationships between NPQ and de-epoxidized xanthophylls in all groups investigated (plants, green algae, diatoms, Chrysophyceae) and under a wide range of

$434 \quad$ experimental conditions.

However, besides $q_{\mathrm{E}}$, NPQ also quantifies the fluorescence quenching caused by state 436 transitions $\left(q_{\mathrm{T}}\right)$ or by photoinhibition $\left(q_{\mathrm{I}}\right)$ which may potentially significantly affect the NPQ vs. 
$E$ curves. $q_{\mathrm{T}}$ is relevant in phycobilisome-containing organisms (cyanobacteria and red algae)

438 (Campbell et al. 1998; Mullineaux and Emlyn-Jones 2004), although not as much in higher

439 plants and green algae (Pfannschmidt 2005; Eberhard et al. 2008; Ruban and Johnson 2009),

440 and it does not occur for the Heterokontophyta (Lavaud 2007). When occurring, $q_{\mathrm{T}}$ is not

$441 \quad$ significant in light conditions triggering $q_{\mathrm{E}}$-related NPQ (Mullineaux and Emlyn-Jones 2004;

442 Tikkanen et al. 2006; Ruban and Johnson 2009). With the exception of some land plants

443 (overwintering conifers and tropical evergreen species), $q_{\mathrm{I}}$ origin is not clearly defined and it

444 requires particular conditions such as prolonged environmental stress (Müller et al. 2001;

445 Demmig-Adams and Adams 2006; Horton et al. 2008).

446 The effects of $q_{\mathrm{T}}$ or $q_{\mathrm{I}}$ on the light-response curve of NPQ would likely consist in a

447 general change in curve shape, through the increase of NPQ at low light levels (for $q_{\mathrm{T}}$ ) and of

$448 \quad \mathrm{NPQ}_{\mathrm{m}}\left(\right.$ for $q_{\mathrm{I}}$ ). However, these components of NPQ may be expected not to significantly affect

449 the NPQ vs. $E$ curves measured under the usually applied experimental protocols. This is

450 because the duration of the light steps commonly applied $(\leq 2-3 \mathrm{~min}$, and much shorter in the

451 case of RLCs) correspond to light doses clearly different than those required to induce both $q_{\mathrm{T}}$

452 or $q_{\mathrm{I}}$ (Campbell et al. 1998; Müller et al. 2001; Demmig-Adams and Adams 2006; Horton et al.

$453 \quad$ 2008; Ruban and Johnson 2009).

The same reasoning applies to another implicit assumption of the model, that during the generation of a light curve $q_{\mathrm{E}}$ is due solely to the development of the $\Delta \mathrm{pH}$ and the subsequent

457 fact, it is well established that exposure to high light can induce the de novo synthesis of XC

458 pigments (e.g. Olaizola and Yamamoto 1994; D’Haese et al. 2004; Lavaud et al. 2004;

459 Demmig-Adams and Adams 2006). This process causes the accumulation of de-epoxidized

460 forms, which could result in the linear increase of NPQ in the high-light part of the curve.

461 Again, the de novo synthesis requires the prolonged exposure to very high irradiances (e.g.

462 Lavaud et al. 2004; Demmig-Adams and Adams 2006; Lavaud 2007), well above the light

463 doses applied during the construction of NPQ light-response curves. 

resulting curve may still be of the same general shape and describable by the model. In fact, this study showed that the model fits very well to data obtained in a wide range of experimental conditions, in which the occurrence of any of these processes cannot be completely ruled out (Table 3). In this case, however, care should be taken in interpreting and comparing the model parameters estimated for different species or condition, as they may be affected differently by

470 processes other than the build-up of the $\Delta \mathrm{pH}$ and the XC. In the case of organisms with 471 impaired operation of the XC (mutants or inhibitor-treated samples), the model was nevertheless 472 shown to be of value, providing a useful quantitative characterization of the light response of $473 \quad$ NPQ.

Another major assumption of the model is that the formation of $q_{\mathrm{E}}$, through the deepoxidation of Vx or DD generated by the acidification of the lumen relates to incident 476 irradiance following the generic conditions of application of the Hill equation, i.e. that NPQ can 477 be considered as allosterically regulated by irradiance through the build-up of the 478 transthylakoidal $\Delta \mathrm{pH}$. This assumption is partially supported by the finding that, in isolated 479 plant chloroplasts, the regulation of $q_{\mathrm{E}}$ is of allosteric nature, resulting in response curves of $q_{\mathrm{E}}$ $480 \quad$ as a function of $\Delta \mathrm{pH}$ of sigmoidal shape, shown to be adequately described by the Hill equation 481 (Pfündel and Dilley 1993; Ruban et al. 2001; Takizawa et al. 2007; Pérez-Bueno et al. 2008). 482 This sigmoidicity is attributed to the protonation of binding sites of the LHC protein Psbs 483 induced by lumen acidification, and subsequent conformational changes within the LHC, 484 switching the de-epoxidized xanthophylls to an 'activated' state. It is taken as an indication of 485 allosteric regulation of $q_{\mathrm{E}}$, resulting from proton binding showing positive cooperativity, and the 'activated' de-epoxidized xanthophylls Zx (Horton et al. 2000; Horton et al. 2008; Li et al. 2009) or DT (Goss et al. 2006; Lavaud and Kroth 2006) acting as a positive effector. The strong physiological basis of the proposed model is likely to explain its success to cope with a large diversity of light-response curve characteristics. Other mathematical models have also been used to successfully describe NPQ vs. $E$ curves, namely an exponential saturation function, the Michaelis-Menten function, and a hyperbolic tangent function (Ritchie 
493 of low sigmoidicity. Interestingly, the model that yielded the better fit to experimental data was 494 the Michaelis-Menten equation (Ritchie 2008), a particular case of the model proposed in the 495 present study. fact that in most cases the curves did not reach a saturation plateau within the range of irradiances applied (e.g. Fig. 1a). When assuming NPQ to represent mostly $q_{\mathrm{E}}$, the maximum NPQ reached by a sample quantifies its photoprotective potential via the dissipation of excessive light energy. By applying the model, curves measured under different experimental conditions can be readily compared, and changes in $\mathrm{NPQ}_{\mathrm{m}}$ (e.g. following changes in growth light conditions) can be quantified, which would be otherwise impossible. The accurate estimation of $\mathrm{NPQ}_{\mathrm{m}}$ is also required for quantifying $E_{50}$, which, in some cases of strict relationship (e.g. for most Heterokontophyta; Lavaud et al. 2004; Lavaud 2007), is interpretable as the light level corresponding to the de-epoxidation and 'activation' of the xanthophyll convertible pool necessary to induce half of the maximal NPQ. The size of the xanthophyll 511 growth conditions, ranging between 50 and 70\% (Lavaud 2007; Goss and Jakob 2010). Again, 512 the fit of Eq. 2 to NPQ vs. $E$ curves provided an adequate form of characterizing how promptly 513 the $\mathrm{XC}$ is $\Delta \mathrm{pH}$-activated when responding to an increase in incident irradiance. curves (at least when saturation is reached for the light levels applied), the curve sigmoidicity 516 can hardly be characterized quantitatively without the fit of the model and estimation of $n$. The 517 sigmoidicity coefficient was found to vary around 1.5-2.0, values corresponding to positive 518 cooperativity and thus indicating the allosteric regulation of NPQ by light. Minimum $n$ values averaged about 1 (reaching significantly lower values only for cases of XC impairment), 
indicate that negative cooperativity is not involved in the regulation of processes underlying

521 NPQ. These results generally support that the allosteric nature known for the more fundamental 522 regulation of $q_{\mathrm{E}}$ by $\Delta \mathrm{pH}$ in plants (Ruban et al. 2001; Li et al. 2009) holds for the relationship of 523 NPQ to irradiance in a large diversity of photosynthetic organisms.

The Hill coefficient has been interpreted as representing the number of allosteric

525 regulators (D'Haese et al. 2004). Considering the diversity of factors likely to contribute to the

526 NPQ vs. $E$ curve (Demmig-Adams and Adams 2006; Eberhard et al. 2008; Horton et al. 2008;

527 Li et al. 2009), some of them not fully identified in some photosynthetic taxa (Lavaud 2007), $n$

528 should be considered simply as an empirical coefficient informing on the degree of allostery and

529 serving as a practical descriptor of the curve shape.

530

$531 \quad$ Relationship of NPQ light response to photoacclimation status

533 The modelling of the NPQ vs. $E$ curves opens the new possibility of quantitatively comparing

534 the light responses of NPQ and of photochemistry or ETR. Photosynthesis and ETR light-

535 response curves are very commonly used as a form of characterizing the photoacclimation status

536 of photosynthetic organisms, through the estimation of the parameters of a number of available models (Henley 1993; Behrenfeld et al. 2004; Ralph and Gademann 2005; Guarini and Moritz 2009; Perkins et al. 2010). By describing the NPQ vs. E curve by a small set of meaningful parameters, the light response of NPQ can be characterized relatively to the one of ETR or

540 photosynthetic rate.

541 This possibility is useful for the definition of the light levels corresponding to the onset 542 of NPQ (e.g. activation of the XC) relatively to the saturation of photochemistry. As the light 543 response of NPQ may depend greatly on the photoacclimation status, the characterization and 544 comparison of NPQ vs. $E$ curves should be preferably normalized to parameters indicative of 545 photochemistry saturation. Furthermore, the comparison of the NPQ and ETR light responses is 546 also of interest because it provides insight on the way an organism combines the responses of 547 photochemistry and of photoprotective processes to changes in ambient light. However, without 
548 adequate parameterization of the NPQ light-response, this question can be answered only

$549 \quad$ approximately.

550 Despite its simplicity, the indices $E_{50} / E_{\mathrm{k}}$ and $\mathrm{NPQ}$ Ek here proposed provide an efficient

551 form of comparing the light levels for which NPQ reaches significant values and

552 photochemistry reaches saturation. The application of these indices allowed quantifying the

553 delay of the light response of NPQ relatively to the saturation of photochemistry. Under the

554 assumption that NPQ mostly represents $q_{\mathrm{E}}$, it showed that it takes about three times the

$555 \quad$ irradiance at $E_{\mathrm{k}}$ for half of $q_{\mathrm{E}}$ to develop and that, at $E_{\mathrm{k}}$, the formation of $q_{\mathrm{E}}$ is still at relatively

556 low levels, providing typically less than one fifth of maximum photoprotective capacity. For the

557 cases when $q_{\mathrm{E}}$ is strictly related to the XC operation (e.g. in most of Heterokontophyta; Lavaud

558 et al. 2004; Lavaud 2007), the values of the indices $E_{50} / E_{\mathrm{k}}$ and $\mathrm{NPQ}_{\mathrm{Ek}}$ can be interpreted in

559 terms of the de-epoxidation state of the convertible pool of xanthophylls and their 'activation'

560 upon LHC protonation. Yet, the modelling of the NPQ vs. E curve may allow for the

561 development of other indices that better characterize this relationship.

562 Interestingly, the meta-analysis carried out in this study showed consistent differences

563 between the relationships of NPQ light response to photoacclimation status in organisms with

564 VAZ and DD-DT types of XC. The fact that these differences were found despite the diversity

565 in taxa and growth conditions may indicate that they are due to fundamental differences in the

566 way the two types of organisms cope with high light, especially regarding the underlying $q_{\mathrm{E}}$

567 mechanism and regulation of the XC, illustrating the advantages provided by the quantitative

568 description of the NPQ vs $E$ curve.

569

570

\section{Acknowledgements}

571

572

573 the Arabidopsis plants. This study was supported by FCT - Fundação para a Ciência e a

574 Tecnologia, grant SFRH/BSAB/962/2009, to J. Serôdio, by the French consortium CPER-

575 Littoral to J. Lavaud, and by the CNRS - Centre National de la Recherche Scientifique 
576 (programme 'chercheurs invités') to both. We thank two anonymous reviewers for critical

577 comments on the manuscript. 

productivity. In: Papageorgiou GC and Govindjee (eds) Chlorophyll $a$ fluorescence: A signature of photosynthesis. Springer, Dordrecht, pp 65-82

584 Behrenfeld MJ, Prasil O, Babin M, Bruyant F (2004) In search of a physiological basis for 585 covariations in light-limited and light-saturated photosynthesis. J Phycol 40:4-25 (2010) An atypical member of the light-harvesting complex stress-related protein family modulates diatom responses to light. Proc. Natl. Acad. Sci. USA 107: 18214-18219 measurements of light-induced absorbance changes, fluorescence and photosynthesis in leaves of Hedera canariensis. Photosynth Res 25:173-185 Burritt DJ, Mackenzie S (2003) Antioxidant metabolism during acclimation of Begonia $\times$ erytrophylla to high light levels. Ann Bot 91:783-794 analysis of cyanobacterial photosynthesis and acclimation. Microbiol Molec Biol Rev 62:667683 
Cruz S, Serôdio J (2008) Relationship of rapid light curves of variable fluorescence to

607 photoacclimation and non-photochemical quenching in a benthic diatom. Aquat Bot 88:256-264

608

609 Demmig-Adams B, Adams WW (2006) Photoprotection in an ecological context: the

610 remarkable complexity of thermal energy dissipation. New Phytol 172:11-21

611

612 D'Haese D, Vandermeiren K, Caubergs RJ, Guisez Y, De Temmerman L, Horemans N. (2004)

613 Non-photochemical quenching kinetics during the dark to light transition in relation to the

614 formation of antheraxanthin and zeaxanthin. J Theor Biol 227:175-186

615

616 Dimier C, Corato F, Saviello G, Brunet C (2007a) Photophysiological properties of the marine

617 picoeukaryote Picochlorum Rcc 237 (Trebouxiophyceae, Chlorophyta). J Phycol 43:275-283

618

619 Dimier C, Corato F, Tramontano F, Brunet C (2007b) Photoprotection and xanthophyll-cycle

620 activity in three marine diatoms. J Phycol 43:937-947

621

622

Eberhard S, Finazzi G, Wollman F (2008) The dynamics of photosynthesis. Ann Rev Gen

623 42:463-515

624

Eilers PH, Peeters JC (1988) A model for the relationship between light intensity and the rate of

626 photosynthesis in phytoplankton. Ecol Model 42:199-215

627

628

Elrad D, Niyogi KK, Grossman AR (2002) A major light-harvesting polypeptide of

629

photosystem II functions in thermal dissipation. Plant Cell 14:1801-1816

630

631 Geel C, Verluis W, Snel JF (1997) Estimation of oxygen evolution by marine phytoplankton

632 from measurement of the efficiency of photosystem II electron flow. Photosynth Res 51:61-70

633 
634 Genty B, Briantais JM, Baker NR (1989) The relationship between the quantum yield of

635 photosynthetic electron transport and quenching of chlorophyll fluorescence. Biochim Biophys

$636 \quad$ Acta $990: 87-92$

637

638 Goss R and Jakob T (2010) Regulation and function of xanthophyll cycle-dependent

639 photoprotection in algae. Photosynth Res In press

640

641 Goss R, Pinto EA, Wilhelm C, Richter M (2006) The importance of a highly active and $\Delta \mathrm{pH}$ -

642 regulated diatoxanthin epoxidase for the regulation of the PS II antenna function in

643 diadinoxanthin cycle containing algae. J Plant Physiol 163:1008-1021

644

645 Guarini J, Moritz C (2009) Modelling the dynamics of the electron transport rate measured by

646 PAM fluorimetry during Rapid Light Curve experiments. Photosynthetica 47:206-214

647

648 Guillard RRL, Ryther JH (1962) Studies of marine phytoplanktonic diatoms. I. Cyclotella nana

649 Hustedt and Detonula confervaceae (Cleve) Gran. Can J Microbiol 8:229-239

650

651

Havaux M, Kloppstech K (2001) The protective functions of carotenoid and flavonoid pigments

652

653 against excess visible radiation at chilling temperature investigated in Arabidopsis $n p q$ and $t t$

654

655

Henley WJ (1993) Measurement and interpretation of photosynthetic light-response curves in

656 algae in the context of photoinhibition and diel changes. J Phycol 29:729-739

657

658 Herlory O, Richard P, Blanchard GF (2007) Methodology of light response curves: application of chlorophyll fluorescence to microphytobenthic biofilms. Mar Biol 153:91-101

660 

plant grana membranes regulate light harvesting states? FEBS J. 275:1069-1079 Biol 1:76-82

671 Johnson ML (2008) Nonlinear least-squares fitting methods. In Correia J, Detrich H (eds) Methods in cell biology, vol 84. Elsevier Academic Press, San Diego, pp 781-805 Arabidopsis. Plant Physiol 150:977-986 primary production in Lake IJsselmeer (The Netherlands) using variable fluorescence (PAMFRRF) and C-uptake techniques. Eur J Phycol 43:327-344

681

682 Kropuenske LR, Mills MM, Dijken GL, Bailey S, Robinson DH, Welschmeyer NA, Arrigo

683 K.R. (2009) Photophysiology in two major Southern Ocean phytoplankton taxa: 
690

Lavaud J (2007) Fast regulation of photosynthesis in diatoms: mechanisms, evolution and ecophysiology. Funct Plant Sci Biotechnol 1:267-287

693

694 Lavaud J, Kroth PG (2006) In diatoms, the transthylakoid proton gradient regulates the 695 photoprotective non-photochemical fluorescence quenching beyond its control on the xanthophyll cycle. Plant Cell Physiol 47:1010-1016

697

Lavaud J, Rousseau B, Etienne AL (2004) General features of photoprotection by energy dissipation in planktonic diatoms (Bacillariophyceae). J Phycol 40:130-137

700

701 Lavaud J, Rousseau B, Gorkom HJ, Etienne A (2002) Influence of the diadinoxanthin pool size on photoprotection in the marine planktonic diatom. Plant Physiol 129:1398-1406

703

Lavaud J, Strzepek RF, Kroth PG (2007) Photoprotection capacity differs among diatoms: Possible consequences on the spatial distribution of diatoms related to fluctuations in the underwater light climate. Limnol Oceanogr 52:1188-1194

707 pigment-binding protein essential for regulation of photosynthetic light harvesting. Nature 403:391-395 
Lokstein H, Tian L, Polle JE, DellaPenna D (2002) Xanthophyll biosynthetic mutants of Arabidopsis thaliana: altered nonphotochemical quenching of chlorophyll fluorescence is due to changes in Photosystem II antenna size and stability. Biochim Biophys Acta 1553:309-319

Marschall M, Proctor MCF (2004) Are bryophytes shade plants? Photosynthetic light responses and proportions of chlorophyll $a$, chlorophyll $b$ and total carotenoids. Ann Bot 94:593-603

Mouget J-L, Tremblin G (2002) Suitability of the Fluorescence Monitoring System (FMS,

Mullineaux CW, Emlyn-Jones D (2005) State transitions: an example of acclimation to lowlight stress. J Exp Bot 56:389-393

Müller P, Li X-P, Niyogi KK (2001) Non-photochemical quenching. A response to excess light energy. Plant Physiol 125:1558-1566

730

Müller-Moulé P, Conklin PL, Niyogi KK (2002) Ascorbate deficiency can limit violaxanthin de-Epoxidase activity in vivo. Plant Physiol 128:970-977 Müller-Moulé P, Golan T, Niyogi KK (2004) Ascorbate-deficient mutants of Arabidopsis grow in high light despite chronic photooxidative stress. Plant Physiol 134:1163-1172 
742 required for accumulation of the chloroplast $\mathrm{NAD}(\mathrm{P}) \mathrm{H}$ dehydrogenase complex in Arabidopsis.

$743 \quad$ Plant Physiol 141:737-744

Niyogi KK, Grossman AR, Björkman O (1998) Arabidopsis mutants define a central role for the xanthophyll cycle in the regulation of photosynthetic energy conversion. Plant Cell 10:1121-

Olaizola M, Yamamoto HY (1994) Short-term response of the diadinoxanthin cycle and fluorescence yield to high irradiance in Chaetoceros muelleri (Bacillariophyceae). J Phycol 30:606-612

Ort DR (2001) When there is too much light. Plant Physiol 125:29-32

Osmond B, Badger M, Maxwell K, Björkman O, Leegood R (1997) Too many photons: photorespiration, photoinhibition and photooxidation. Trends Plant Sci 2:119-121 (2009) An ancient light-harvesting protein is critical for the regulation of algal photosynthesis.

$760 \quad$ Nature 462:518-522 xanthophyll composition of the light harvesting antenna controls the $\Delta \mathrm{pH}$-dependency of nonphotochemical quenching in Arabidopsis thaliana. FEBS Lett 582:1477-1482 (2010) The application of variable chlorophyll fluorescence to microphytobenthic biofilms. In: 
Perkins RG, Mouget J-L, Lefebvre S, Lavaud J (2006) Light response curve methodology and possible implications in the application of chlorophyll fluorescence to benthic diatoms. Mar Biol 149:703-712

775

776

777

Pfannschmidt T (2005) Acclimation to varying light qualities: toward the functional relationship 778

Pfündel EE, Dilley RA (1993) The pH dependence of violaxanthin deepoxidation in isolated pea chloroplasts. Plant Physiol 101:65-71

781

Press WH, Teukolsky S, Vetterling W, Flannery B (1996) Numerical recipes in Fortran 90. The Art of Parallel Scientific Computing. $2^{\text {nd }}$ ed Cambridge University Press, Cambridge

784

785

Ralph PJ, Gademann R (2005) Rapid light curves: a powerful tool to assess photosynthetic activity. Aquat Bot 82:222-237

Ralph PJ, Gademann R, Larkum AW (2001) Zooxanthellae expelled from bleached corals at 33 ${ }^{\circ} \mathrm{C}$ are photosynthetically competent. Marine Ecology Progress Series 220:163-168

790

Ritchie RJ (2008) Fitting light saturation curves measured using modulated fluorometry. Photosynth Res 96:201-215

Rodríguez-Calcerrada J, Pardos JA, Gil L, Aranda I (2007) Acclimation to light in seedlings of Quercus petraea (Mattuschka) Liebl. and Quercus pyrenaica Willd. planted along a forest-edge gradient. Trees 21:45-54 

with state transitions. Photosynth Res 99:173-183

800

Ruban AV, Wentworth M, Horton P (2001) Kinetic analysis of nonphotochemical quenching of

802 chlorophyll fluorescence. 1. Isolated chloroplasts. Biochemistry 40:9896-9901

803

804 Serôdio J, Vieira S, Cruz S, Coelho H (2006) Rapid light-response curves of chlorophyll

805 fluorescence in microalgae: relationship to steady-state light curves and non-photochemical

806 quenching in benthic diatom-dominated assemblages. Photosynth Res 90:29-43

807

808 Takizawa K, Cruz JA, Kanazawa A, Kramer DM (2007) The thylakoid proton motive force in

809 vivo. Quantitative, noninvasive probes, energetics, and regulatory consequences of light-induced

$810 \quad$ pmf. Biochim Biophys Acta 1767:1233-1244

811

812 Tellinghuisen J (2008) Stupid statistics! In Correia J, Detrich H (eds) Methods in cell biology,

813 vol 84. Elsevier Academic Press, San Diego, pp 739-780

814

815 Tikkanen M, Pippo M, Suorsa M, Sirpio S, Mulo P, Vainonen J, Vener A, Allahverdiyeva Y,

816 Aro EM (2006) State transitions revisited - a buffering system for dynamic low light

817 acclimation of Arabidopsis. Plant Molec Biol 62:779-793

818

819 Voet D, Voet JG (1990) Biochemistry. John Wiley and Sons, New York 
821

$822 \alpha-$ Initial slope of the ETR vs. $E$ curve

$823 \quad$ Ax - Antheraxanthin

824 DD - Diadinoxanthin

825 DT - Diatoxanthin

$826 E-$ PAR irradiance $\left(\mu \mathrm{mol}\right.$ photons $\left.\mathrm{m}^{-2} \mathrm{~s}^{-1}\right)$

$827 \quad E_{50}-$ Irradiance level corresponding to $50 \%$ of $\mathrm{NPQ}_{\mathrm{m}}$ in a NPQ vs. $E$ curve

$828 E_{\mathrm{k}}-$ Light-saturation parameter of the ETR vs. $E$ curve

$829 \quad$ ETR - PSII relative electron transport rate

$830 \quad \mathrm{ETR}_{\mathrm{m}}-$ Maximum ETR in a ETR vs. $E$ curve

$831 F_{\mathrm{o}}, F_{\mathrm{m}}-$ Minimum and maximum fluorescence of a dark-adapted sample

$832 F_{\mathrm{s}}, F_{\mathrm{m}}{ }^{\prime}-$ Steady state and maximum fluorescence of a light-adapted sample

833 NPQ - Non-photochemical quenching

$834 \mathrm{NPQ}_{\mathrm{m}}-$ Maximum NPQ value reached in a NPQ vs. $E$ curve

$835 \mathrm{NPQ}_{\mathrm{Ek}}-$ Fraction of $\mathrm{NPQ}_{\mathrm{m}}$ reached when $E=E_{\mathrm{k}}$

$836 n$-Sigmoidicity coefficient of the NPQ vs. $E$ curve

$837 \quad$ PSII - Photosystem II

$838 \quad$ RLC - Rapid light-response curve

$839 \quad$ VAZ - Vx-Ax-Zx XC

$840 \quad$ Vx - Violaxanthin

841 XC - Xanthophyll cycle

$842 \quad$ Zx - Zeaxanthin

843 
845 Table 2. Summary of the results of the fitting of the model to NPQ vs. $E$ curves measured in $A$.

846 thaliana and N. palea grown under low (LL), moderate (ML) and high light (HL). Parameter

$847 \quad$ estimates \pm one standard error.

848

Model parameters

\begin{tabular}{|c|c|c|c|c|c|}
\hline & & $\mathrm{NPQ}_{\mathrm{m}}$ & $E_{50}$ & $\mathrm{n}$ & $r^{2}$ \\
\hline \multirow[t]{3}{*}{ A. thaliana } & LL & $3.91 \pm 0.82$ & $209.9 \pm 8.31$ & $1.44 \pm 0.52$ & 0.999 \\
\hline & ML & $4.63 \pm 0.24$ & $542.0 \pm 49.2$ & $1.21 \pm 0.04$ & 0.999 \\
\hline & HL & $5.90 \pm 1.04$ & $1141.0 \pm 372.1$ & $0.98 \pm 0.06$ & 0.998 \\
\hline \multirow[t]{3}{*}{ N. palea } & LL & $2.70 \pm 0.10$ & $91.7 \pm 7.01$ & $1.61 \pm 0.19$ & 0.991 \\
\hline & ML & $3.65 \pm 0.05$ & $312.6 \pm 5.59$ & $2.16 \pm 0.05$ & 0.999 \\
\hline & HL & $3.86 \pm 0.11$ & $551.4 \pm 15.8$ & $2.55 \pm 0.08$ & 0.999 \\
\hline
\end{tabular}

849 
Model parameters

\begin{tabular}{|c|c|c|c|c|c|c|c|c|c|}
\hline XC type & Taxon & & $\mathrm{LC}$ & Treatment & $\mathrm{NPQ}_{\mathrm{m}}$ & $\mathrm{E}_{50}$ & $\mathrm{n}$ & $r^{2}$ & Reference \\
\hline \multirow[t]{3}{*}{ VAZ } & $\begin{array}{l}\text { Magnoliophyta } \\
\text { (flowering plants) }\end{array}$ & Arabidopsis thaliana & SS & $\begin{array}{l}\text { wt } 10^{\circ} \mathrm{C} \\
\text { wt } 25^{\circ} \mathrm{C} \\
n p q 110^{\circ} \mathrm{C} \\
n p q 125^{\circ} \mathrm{C}\end{array}$ & $\begin{array}{l}2.07 \pm 0.04 \\
2.98 \pm 0.40 \\
1.68 \pm 0.25 \\
1.16 \pm 0.22\end{array}$ & $\begin{array}{c}113.6 \pm 6.0 \\
1118.0 \pm 293.8 \\
636.5 \pm 587.0 \\
867.1 \pm 557.5\end{array}$ & $\begin{array}{l}1.11 \pm 0.08 \\
1.09 \pm 0.11 \\
0.40 \pm 0.06 \\
0.63 \pm 0.10\end{array}$ & $\begin{array}{l}0.998 \\
0.996 \\
0.998 \\
0.995\end{array}$ & $\begin{array}{l}\text { Havaux and } \\
\text { Kloppstech } \\
(2001)\end{array}$ \\
\hline & & & SS & $\begin{array}{l}\text { Li-1 } \\
\text { Sf-2 } \\
\text { Col-0 } \\
\text { Ws-2 }\end{array}$ & $\begin{array}{l}3.76 \pm 0.18 \\
4.12 \pm 0.16 \\
3.29 \pm 0.19 \\
3.32 \pm 0.19\end{array}$ & $\begin{array}{l}563.8 \pm 40.6 \\
661.9 \pm 33.7 \\
683.7 \pm 55.0 \\
599.8 \pm 49.1\end{array}$ & $\begin{array}{l}1.83 \pm 0.16 \\
2.03 \pm 0.13 \\
1.84 \pm 0.16 \\
1.96 \pm 0.21\end{array}$ & $\begin{array}{l}0.998 \\
0.999 \\
0.998 \\
0.997\end{array}$ & $\begin{array}{l}\text { Jung and } \\
\text { Niyogi (2009) }\end{array}$ \\
\hline & & & SS & $\begin{array}{l}\text { wt } \\
\text { lut1 } \\
\text { lut } 2 \\
\text { abal } \\
\text { lut } 2 a b a l\end{array}$ & $\begin{array}{l}2.06 \pm 0.08 \\
1.52 \pm 0.06 \\
1.76 \pm 0.10 \\
2.36 \pm 0.19 \\
1.17 \pm 0.07\end{array}$ & $\begin{array}{l}184.1 \pm 13.4 \\
195.5 \pm 13.7 \\
231.0 \pm 22.2 \\
251.1 \pm 43.2 \\
214.7 \pm 30.6\end{array}$ & $\begin{array}{l}2.21 \pm 0.32 \\
2.28 \pm 0.33 \\
1.72 \pm 0.22 \\
1.14 \pm 0.13 \\
1.08 \pm 0.10\end{array}$ & $\begin{array}{l}0.993 \\
0.994 \\
0.995 \\
0.996 \\
0.997\end{array}$ & $\begin{array}{l}\text { Lokstein et al. } \\
(2002)\end{array}$ \\
\hline
\end{tabular}




\begin{tabular}{|c|c|c|c|c|c|c|c|}
\hline & SS & $\begin{array}{l}\mathrm{wt} \\
v t c 2\end{array}$ & $\begin{array}{l}3.22 \pm 0.22 \\
3.86 \pm 0.22\end{array}$ & $\begin{array}{c}822.2 \pm 90.9 \\
1606.8 \pm 137.5\end{array}$ & $\begin{array}{l}1.46 \pm 0.15 \\
1.32 \pm 0.05\end{array}$ & $\begin{array}{l}0.993 \\
0.957\end{array}$ & $\begin{array}{l}\text { Müller-Moulé } \\
\text { et al. (2002) }\end{array}$ \\
\hline & SS & $\begin{array}{l}\text { wt LL } \\
v t c 2 \mathrm{LL} \\
v t c 2 n p q 4 \mathrm{LL} \\
v t c 2 n p q 1 \mathrm{LL} \\
\text { wt } \mathrm{HL} \\
v t c 2 \mathrm{HL} \\
v t c 2 n p q 4 \mathrm{HL} \\
v t c 2 n p q 1 \mathrm{HL}\end{array}$ & $\begin{array}{l}2.99 \pm 0.22 \\
4.52 \pm 1.08 \\
2.03 \pm 0.32 \\
2.51 \pm 1.41 \\
4.55 \pm 6.55 \\
6.82 \pm 2.35 \\
1.82 \pm 1.00 \\
1.80 \pm 1.84\end{array}$ & $\begin{array}{c}993.6 \pm 96.6 \\
2492.1 \pm 700.8 \\
2556.4 \pm 402.8 \\
2597.0 \pm 1777.5 \\
4082.0 \pm 5997.8 \\
4133.0 \pm 1851.3 \\
3527.3 \pm 2314.0 \\
3502.8 \pm 4087.1\end{array}$ & $\begin{array}{l}1.95 \pm 0.21 \\
1.49 \pm 0.15 \\
1.73 \pm 0.08 \\
1.43 \pm 0.26 \\
1.47 \pm 0.37 \\
1.24 \pm 0.10 \\
1.39 \pm 0.21 \\
1.39 \pm 0.32\end{array}$ & $\begin{array}{l}0.998 \\
0.999 \\
0.991 \\
0.998 \\
0.998 \\
0.999 \\
0.996 \\
0.996\end{array}$ & $\begin{array}{l}\text { Müller-Moulé } \\
\text { et al. (2004) }\end{array}$ \\
\hline & $\mathrm{SS}$ & $\begin{array}{l}\text { wt } \\
\operatorname{pgr} 5\end{array}$ & $\begin{array}{l}2.21 \pm 0.10 \\
1.77 \pm 3.20\end{array}$ & $\begin{array}{c}457.0 \pm 26.5 \\
1478.1 \pm 5634.7\end{array}$ & $\begin{array}{l}1.48 \pm 0.16 \\
0.81 \pm 0.45\end{array}$ & $\begin{array}{l}0.993 \\
0.957\end{array}$ & $\begin{array}{l}\text { Munekage et } \\
\text { al. (2002) }\end{array}$ \\
\hline & SS & $\begin{array}{l}\text { wt } \\
\text { crr6 } \\
\text { crr6CRR6 }\end{array}$ & $\begin{array}{l}2.25 \pm 0.11 \\
2.00 \pm 0.07 \\
2.01 \pm 0.08\end{array}$ & $\begin{array}{l}503.2 \pm 39.4 \\
397.7 \pm 22.5 \\
365.2 \pm 24.2\end{array}$ & $\begin{array}{l}1.44 \pm 0.07 \\
1.60 \pm 0.08 \\
1.65 \pm 0.11\end{array}$ & $\begin{array}{l}0.999 \\
0.999 \\
0.999\end{array}$ & $\begin{array}{l}\text { Munshi et al. } \\
(2006)\end{array}$ \\
\hline & SS & $\begin{array}{l}\text { wt } \\
n p q 1 \\
n p q 2\end{array}$ & $\begin{array}{l}4.47 \pm 1.24 \\
1.92 \pm 0.81 \\
3.23 \pm 0.35\end{array}$ & $\begin{array}{c}1894.4 \pm 746.9 \\
1877.4 \pm 1686.5 \\
1156.2 \pm 207.4\end{array}$ & $\begin{array}{l}1.34 \pm 0.17 \\
0.90 \pm 0.18 \\
1.32 \pm 0.11\end{array}$ & $\begin{array}{l}0.995 \\
0.988 \\
0.997\end{array}$ & $\begin{array}{l}\text { Niyogi et al. } \\
\text { (1998) }\end{array}$ \\
\hline Begonia $\times$ erythrophylla & $\mathrm{SS}$ & $\begin{array}{l}\mathrm{LL} \\
\mathrm{LL} / \mathrm{HL} \\
\mathrm{HL}\end{array}$ & $\begin{array}{l}1.27 \pm 0.04 \\
1.77 \pm 0.05 \\
2.83 \pm 0.17\end{array}$ & $\begin{array}{l}388.3 \pm 14.1 \\
467.3 \pm 15.8 \\
618.3 \pm 38.6\end{array}$ & $\begin{array}{l}3.51 \pm 0.36 \\
2.95 \pm 0.23 \\
2.82 \pm 0.32\end{array}$ & $\begin{array}{l}0.992 \\
0.997 \\
0.995\end{array}$ & $\begin{array}{l}\text { Burritt and } \\
\text { Mackenzie } \\
\text { (2003) }\end{array}$ \\
\hline Hedera canariensis & SS & $\begin{array}{l}\text { LL } \\
\text { LL+DTT } \\
\text { HL } \\
\text { HL+DTT }\end{array}$ & $\begin{array}{l}3.61 \pm 0.04 \\
1.14 \pm 0.18 \\
5.34 \pm 0.33 \\
1.48 \pm 0.05\end{array}$ & $\begin{array}{c}382.6 \pm 6.3 \\
656.2 \pm 218.9 \\
761.1 \pm 59.6 \\
437.0 \pm 27.8\end{array}$ & $\begin{array}{l}2.90 \pm 0.13 \\
1.09 \pm 0.20 \\
2.05 \pm 0.24 \\
2.20 \pm 0.26\end{array}$ & $\begin{array}{l}0.999 \\
0.987 \\
0.996 \\
0.994\end{array}$ & $\begin{array}{l}\text { Bilger and } \\
\text { Björkman } \\
(1990)\end{array}$ \\
\hline Quercus petraea & SS & $\begin{array}{l}\text { Dense } \\
\text { Edge }\end{array}$ & $\begin{array}{l}2.23 \pm 0.03 \\
5.55 \pm 0.11\end{array}$ & $\begin{array}{l}158.2 \pm 6.35 \\
423.2 \pm 13.3\end{array}$ & $\begin{array}{l}1.83 \pm 0.13 \\
2.04 \pm 0.10\end{array}$ & $\begin{array}{l}0.998 \\
0.999\end{array}$ & $\begin{array}{l}\text { Rodríguez- } \\
\text { Calcerrada et } \\
\text { al. (2007) }\end{array}$ \\
\hline
\end{tabular}




\begin{tabular}{|c|c|c|c|c|c|c|c|c|c|}
\hline & & Zostera marina & $\begin{array}{l}\text { SS } \\
\text { SS } \\
\text { RLC5 } \\
\text { RLC10 } \\
\text { RLC40 }\end{array}$ & $\begin{array}{l}\text { LL } \\
\text { HL } \\
\text { HL } \\
\text { HL } \\
\text { HL }\end{array}$ & $\begin{array}{l}0.87 \pm 0.15 \\
3.12 \pm 0.25 \\
1.36 \pm 0.06 \\
2.34 \pm 0.17 \\
3.37 \pm 0.15\end{array}$ & $\begin{array}{c}797.3 \pm 302.0 \\
400.5 \pm 65.3 \\
276.9 \pm 26.9 \\
399.0 \pm 60.7 \\
360.7 \pm 30.4\end{array}$ & $\begin{array}{l}1.01 \pm 0.14 \\
1.30 \pm 0.16 \\
1.39 \pm 0.17 \\
1.02 \pm 0.11 \\
1.45 \pm 0.12\end{array}$ & $\begin{array}{l}0.995 \\
0.995 \\
0.997 \\
0.997 \\
0.998\end{array}$ & $\begin{array}{l}\text { Ralph and } \\
\text { Gademann } \\
\text { (2005) }\end{array}$ \\
\hline & $\begin{array}{l}\text { Bryophyta } \\
\text { (mosses) }\end{array}$ & $\begin{array}{l}\text { Eurhynchium crassinervium } \\
\text { Pogonatum urnigerum } \\
\text { Polytrichum juniperinum } \\
\text { Tortula (Syntrichia) ruralis } \\
\text { Racomitrium aquaticum } \\
\text { Trichocolea tomentella }\end{array}$ & SS & & $\begin{array}{c}5.79 \pm 0.58 \\
5.45 \pm 0.48 \\
5.90 \pm 0.34 \\
12.23 \pm 0.42 \\
26.27 \pm 3.23 \\
1.45 \pm 0.06\end{array}$ & $\begin{array}{c}237.9 \pm 34.7 \\
584.7 \pm 65.2 \\
689.3 \pm 34.3 \\
458.6 \pm 16.5 \\
830.8 \pm 92.8 \\
68.7 \pm 4.5\end{array}$ & $\begin{array}{l}1.53 \pm 0.12 \\
1.79 \pm 0.15 \\
2.68 \pm 0.17 \\
2.61 \pm 0.15 \\
2.33 \pm 0.18 \\
2.36 \pm 0.33\end{array}$ & $\begin{array}{l}0.998 \\
0.998 \\
0.998 \\
0.999 \\
0.999 \\
0.992\end{array}$ & $\begin{array}{l}\text { Marschall and } \\
\text { Proctor (2004) }\end{array}$ \\
\hline & \multirow[t]{2}{*}{$\begin{array}{l}\text { Chlorophyta } \\
\text { (green algae) }\end{array}$} & Chara corallina & SS & & $1.67 \pm 0.04$ & $34.0 \pm 0.5$ & $6.80 \pm 0.73$ & 0.993 & $\begin{array}{l}\text { Krupenina and } \\
\text { Bulychev } \\
\text { (2007) }\end{array}$ \\
\hline & & Chlamydomonas reinhardtii & SS & $\begin{array}{l}\text { wt } \\
n p q 5\end{array}$ & $\begin{array}{l}1.83 \pm 1.46 \\
0.19 \pm 0.01\end{array}$ & $\begin{aligned} 1010.0 & \pm 1660.0 \\
56.2 & \pm 3.58\end{aligned}$ & $\begin{array}{l}0.81 \pm 0.15 \\
3.66 \pm 0.74\end{array}$ & $\begin{array}{l}0.992 \\
0.986\end{array}$ & $\begin{array}{l}\text { Elrad et al. } \\
(2002)\end{array}$ \\
\hline \multirow[t]{3}{*}{ DD-DT } & $\begin{array}{l}\text { Bacillariophycea } \\
\text { (diatoms) }\end{array}$ & $\begin{array}{l}\text { Chaetoceros socialis } \\
\text { Skeletonema marinoi } \\
\text { Thalassiosira rotula }\end{array}$ & SS & & $\begin{array}{l}5.71 \pm 0.08 \\
1.27 \pm 0.03 \\
1.14 \pm 0.18\end{array}$ & $\begin{array}{c}149.4 \pm 4.8 \\
233.0 \pm 9.3 \\
198.9 \pm 89.8\end{array}$ & $\begin{array}{l}1.88 \pm 0.10 \\
1.95 \pm 0.13 \\
0.89 \pm 0.23\end{array}$ & $\begin{array}{l}0.999 \\
0.998 \\
0.977\end{array}$ & $\begin{array}{l}\text { Dimier et al. } \\
\text { (2007b) }\end{array}$ \\
\hline & & Fragilariopsis cylindrus & SS & $\begin{array}{l}5 \mu \mathrm{mol} \mathrm{m} \mathrm{m}^{-2} \mathrm{~s}^{-1} \\
65 \mu \mathrm{mol} \mathrm{m} \mathrm{m}^{-2} \mathrm{~s}^{-1} \\
125 \mu \mathrm{mol} \mathrm{m} \mathrm{s}^{-1}\end{array}$ & $\begin{array}{l}1.00 \pm 0.18 \\
0.74 \pm 0.08 \\
0.59 \pm 0.12\end{array}$ & $\begin{array}{c}637.5 \pm 266.1 \\
1023.1 \pm 233.6 \\
1024.5 \pm 540.6\end{array}$ & $\begin{array}{c}1.08 \pm 0.23 \\
1.05 \pm 0.9 \\
0.94 \pm 0.13\end{array}$ & $\begin{array}{l}0.966 \\
0.996 \\
0.986\end{array}$ & $\begin{array}{l}\text { Kropuenske et } \\
\text { al. (2009) }\end{array}$ \\
\hline & & Phaeodactylum tricornutum & SS & & $2.30 \pm 0.10$ & $367.6 \pm 24.1$ & $2.59 \pm 0.45$ & 0.984 & Lavaud et al. \\
\hline
\end{tabular}


Skeletonema costatum

Thalassiosira. oceanica

Thalassiosira pseudonana

Thalassiosira weissflogii

Navicula phyllepta

Nitzschia palea
Phaeodactylum tricornutum
$2.77 \pm 0.75$

$0.88 \pm 0.13$

$1.05 \pm 0.04$

$1.58 \pm 0.03$

$9.30 \pm 0.10$

$2.16 \pm 0.08$

$0.19 \pm 0.06$

$0.54 \pm 0.07$

$0.91 \pm 54.5$

$2.90 \pm 0.57$

RLC30

RLC60

SS

SS

$3.48 \pm 0.17$
$2825.9 \pm 1569.0$ $859.4 \pm 282.2$

$276.8 \pm 18.4$

$227.1 \pm 8.3$

$288.5 \pm 6.2$

$334.4 \pm 17.2$

$1057.6 \pm 731.3$

$972.2 \pm 370.1$

$450.0 \pm 54.5$

$1152.8 \pm 463.0$

$5.62 \pm 0.24$

$115.8 \pm 12.2$

$399.9 \pm 27.1$

LL
HL

RLC5 $\quad 25^{\circ} \mathrm{C}$

$25^{\circ} \mathrm{C}$
$33^{\circ} \mathrm{C}$

$33^{\circ} \mathrm{C}$
$37^{\circ} \mathrm{C}$

$38^{\circ} \mathrm{C}$

$0.15 \pm 0.01$

$0.53 \pm 0.05$

$1.20 \pm 0.05$

$0.37 \pm 0.01$

$143.3 \pm 10.5$

$143.3 \pm 10.5$

$115.8 \pm 22.5$

$77.3 \pm 6.7$

$39.9 \pm 2.2$

$39.9 \pm 2.2$

Haptophyta

Phaeocystis antarctica

SS

$5 \mu \mathrm{mol} \mathrm{m} \mathrm{m}^{-2} \mathrm{~s}^{-1} \quad 0.27 \pm 0.03$

$65 \mu \mathrm{mol} \mathrm{m}^{-2} \mathrm{~s}^{-1} \quad 1.49 \pm 1.01$

$426.7 \pm 49.7$

$2953.0 \pm 3309.0$

$755.1 \pm 175.0$

$349.2 \pm 17.8$

$546.2 \pm 35.5$

$5.07+0.52$

$546.6 \pm 85.5$ $446.4 \pm 21.9$

\begin{tabular}{|c|c|c|c|c|c|c|c|c|}
\hline \multirow[t]{2}{*}{ Composite } & Microphytobenthos & \multicolumn{2}{|c|}{$\begin{array}{l}\text { RLC50 } \\
\text { N-SLC }\end{array}$} & $\begin{array}{l}4.09 \pm 0.12 \\
3.72 \pm 0.13\end{array}$ & $\begin{array}{l}349.2 \pm 17.8 \\
546.2 \pm 35.5\end{array}$ & $\begin{array}{l}2.39 \pm 0.26 \\
1.49 \pm 0.10\end{array}$ & $\begin{array}{l}0.994 \\
0.996\end{array}$ & $\begin{array}{l}\text { Herlory et al. } \\
(2007)\end{array}$ \\
\hline & Phytoplankton & SS & $\begin{array}{l}\text { No mixing } \\
\text { Mixing }\end{array}$ & $\begin{array}{l}5.07 \pm 0.52 \\
1.85 \pm 0.09\end{array}$ & $\begin{array}{l}546.6 \pm 85.5 \\
446.4 \pm 21.9\end{array}$ & $\begin{array}{l}1.42 \pm 0.13 \\
2.73 \pm 0.24\end{array}$ & $\begin{array}{l}0.998 \\
0.997\end{array}$ & $\begin{array}{l}\text { Kromkamp et } \\
\text { al. (2008) }\end{array}$ \\
\hline
\end{tabular}

$0.86 \pm 0.08 \quad 0.998$

$0.95 \pm 0.13 \quad 0.992$

$1.96 \pm 0.22 \quad 0.993$

$2.70 \pm 0.22 \quad 0.996$

$2.77 \pm 0.16 \quad 0.999$

$\begin{array}{lll}0.980 & \text { (2002) }\end{array}$

$\begin{array}{lll}1.01 \pm 0.36 & 0.976 & \text { Perkins et al. }\end{array}$

$0.73 \pm 0.11 \quad 0.997 \quad$ (2006)

$1.55 \pm 0.28 \quad 0.990$

$1.10 \pm 0.26 \quad 0.989$

$1.38 \pm 0.15$

$1.58 \pm 0.08$

0.991 Cruz and

Serôdio

(2008)

$\begin{array}{lll}2.39 \pm 0.32 & 0.996 & \text { Ralph et al. }\end{array}$

$1.21 \pm 22.5 \quad 0.994 \quad$ (2001)

$1.18 \pm 0.08 \quad 0.998$

$1.66 \pm 0.17 \quad 0.995$ 
860 NPQ vs. $E$ curves (listed in Table 3 ). Mean values \pm one standard error.

861

Model parameters

\begin{tabular}{cccc} 
XC type & $\mathrm{NPQ}_{\mathrm{m}}$ & $E_{50}$ & $\mathrm{n}$ \\
\hline VAZ & $3.30 \pm 0.49$ & $926.7 \pm 135.1$ & $1.77 \pm 0.13$ \\
DD-DT & $1.88 \pm 0.41$ & $657.9 \pm 145.9$ & $1.60 \pm 0.14$ \\
Mixed & $3.68 \pm 0.67$ & $472.1 \pm 47.3$ & $2.01 \pm 0.33$ \\
\hline All & $2.89 \pm 0.35$ & $824.3 \pm 99.2$ & $1.73 \pm 0.09$
\end{tabular}

862 
Figure legends

865

866

Fig. 1. Fitting of Eq. 2 to light-response curves of NPQ measured in the plant A. thaliana grown under low (LL), moderate (ML) and high light (HL). a. Light-response curves (data points), fitted model (lines), and estimates of model parameters. b. Residuals of the model fitting.

Fig. 2. Fitting of Eq. 2 to light-response curves of NPQ measured in the diatom N. palea grown under low (LL), moderate (ML) and high light (HL). a. Light-response curves (data points), fitted model (lines), and estimates of model parameters. b. Residuals of the model fitting.

873

Fig. 3. Comparison between the light-response curves of NPQ and of ETR of A. thaliana grown under low (LL), moderate (ML) and high light (HL). Estimates of the parameters of the model of Eilers and Peeters (1988) fitted to the ETR vs. $E$ curves are presented. Estimates of the parameters of the curves fitted to the NPQ vs. $E$ curves are presented in Table 2.

878 Fig. 4. Comparison between the light-response curves of NPQ and ETR of N. palea grown under low (LL), moderate (ML) and high light (HL). Estimates of the parameters of the model of Eilers and Peeters (1988) fitted to the ETR vs. $E$ curves are presented. Estimates of the parameters of the curves fitted to the NPQ vs. $E$ curves are presented in Table 2.

883 parameter $E_{\mathrm{k}}$ of the Eilers and Peeters (1988) model fitted to the ETR vs. $E$ curves, for the plant (gray) and low light (black). 
891 response curves of NPQ and ETR in VAZ and DD-DT types of XC. Bars represent one standard

892 error, boxes represent the lower (25\%) and upper (75\%) quartiles, and the thin and thick

893 horizontal lines inside the boxes represent the mean and the median, respectively.

894 
Figure 1
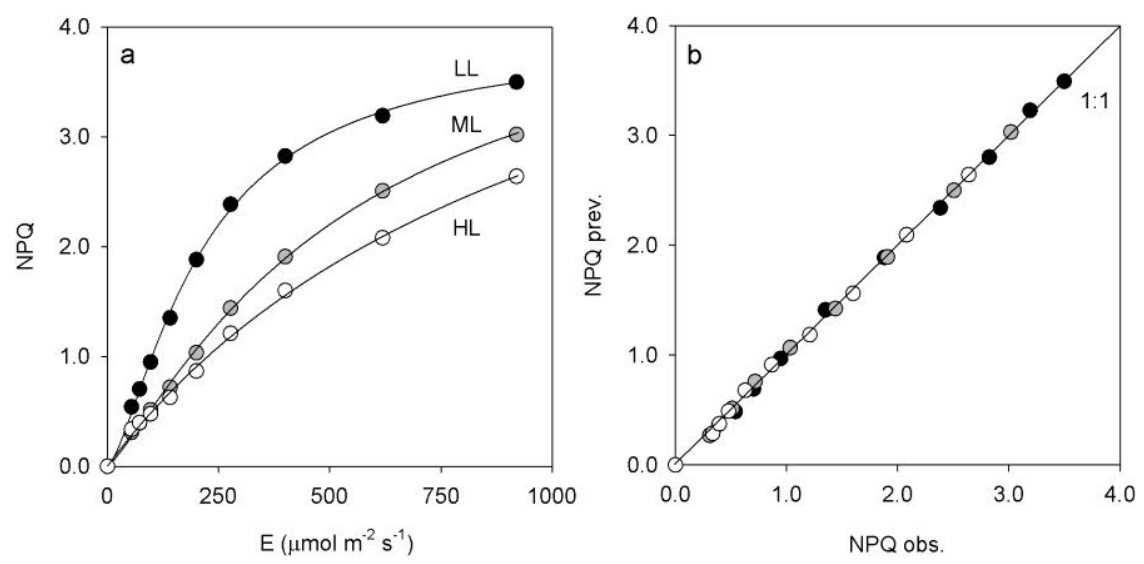

896

897

898 
Figure 2
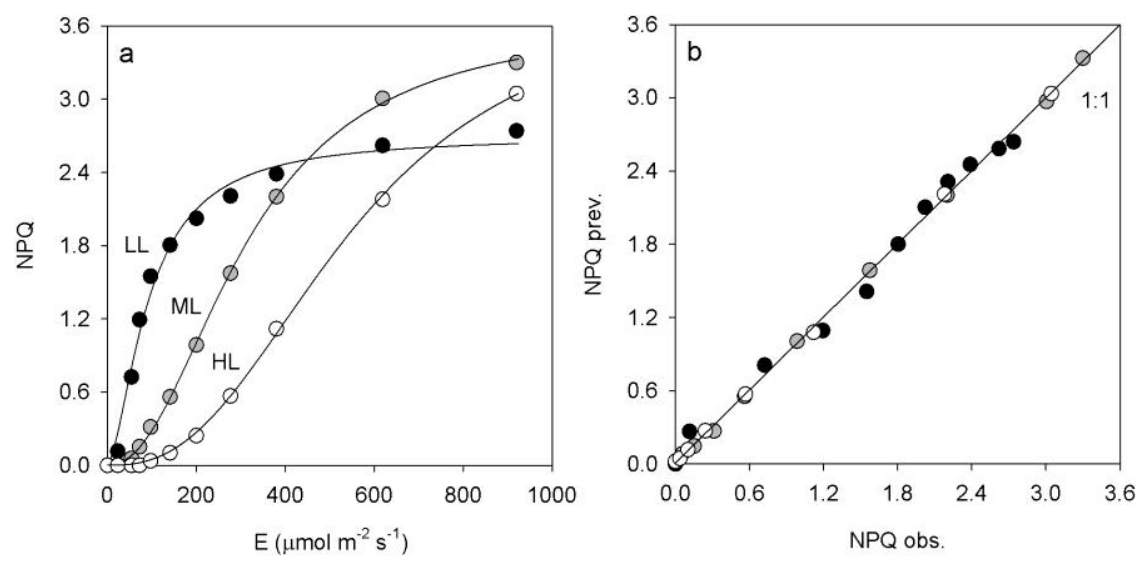

900 
Figure 3

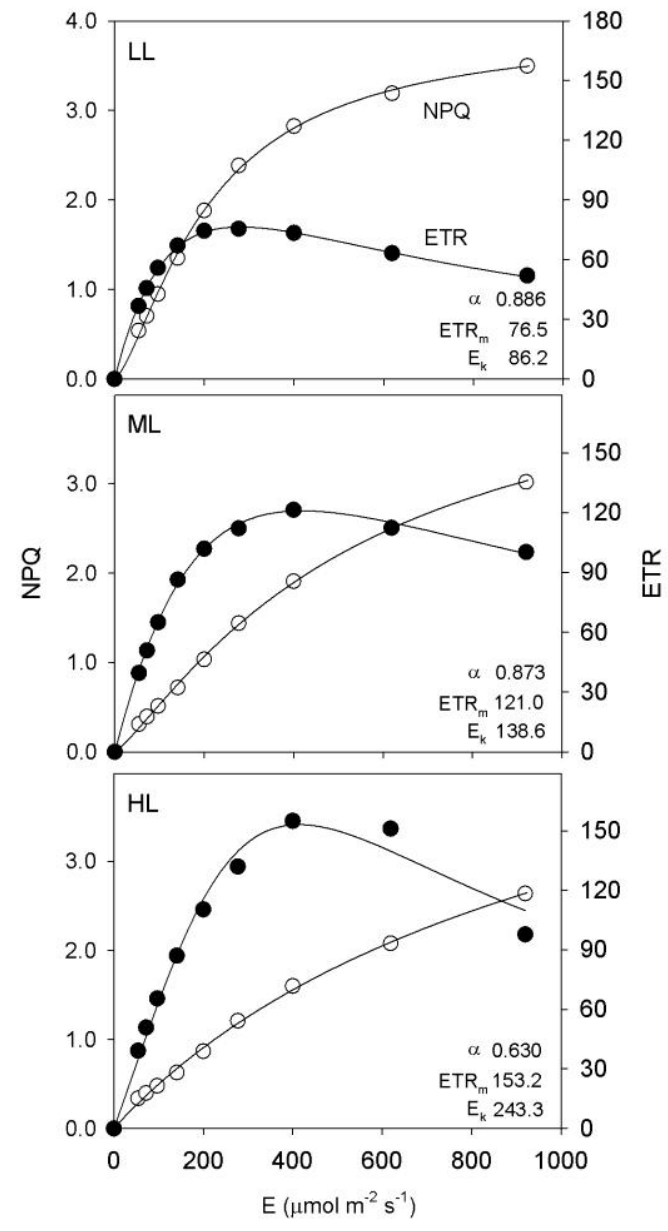


Figure 4

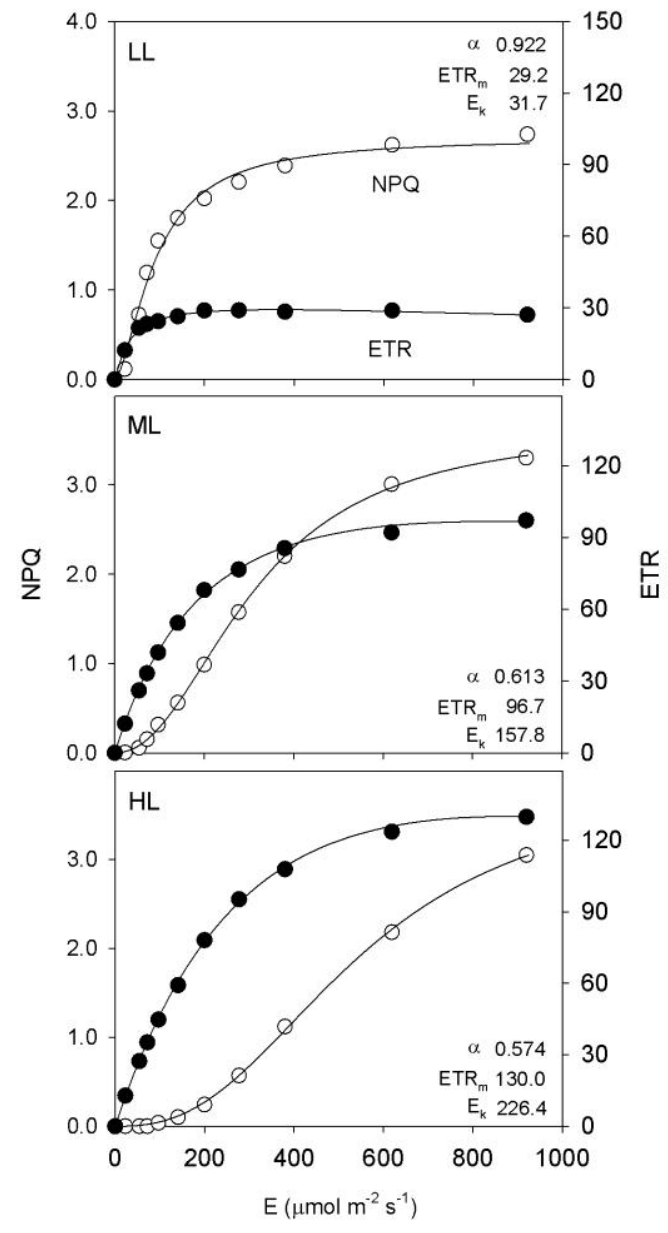

906

907 
Figure 5

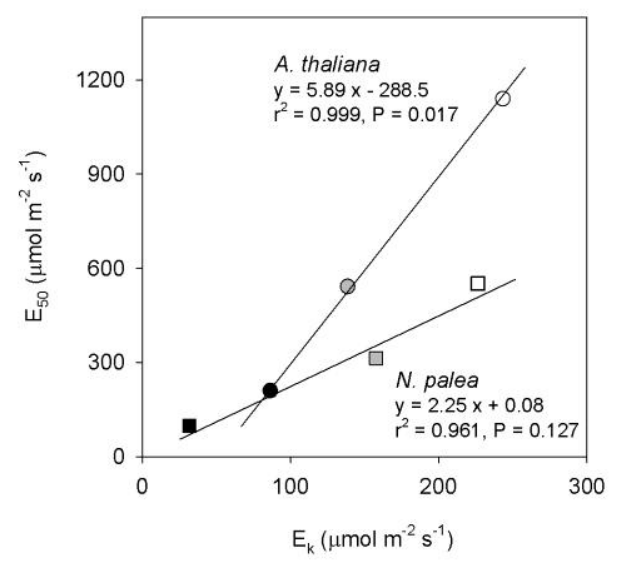

909

910 
Figure 6

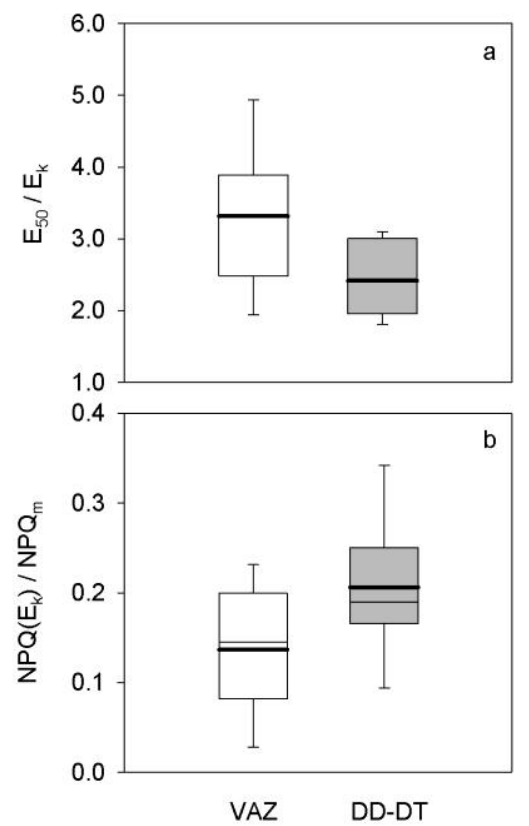

